\title{
Based on the Traditional Culture of Conservation and Renewal of the Space of Urban Fringe Area of Public Cultural Facilities Planning Study
}

\author{
Xuefeng ZHAO \\ Shenyang University \\ Shenyang, China \\ e-mail:446489101@qq.com
}

\author{
Yan HUANG \\ GS Research Center of Shenyang Jianzhu University \\ Shenyang, China \\ e-mail: 1213299329@qq.com
}

\begin{abstract}
This article updates from the protection of traditional culture and use of space angle, to explore the urban fringe community in the process of development of public cultural construction, how to reasonable use of the traditional culture space, to achieve the function of traditional cultural space culture continuation and regeneration in the process of urbanization.
\end{abstract}

Keywords-cultural protection; functional regeneration; cultural facilities; marginal communities; Hakka culture

\section{The Status Quo of Public Cultural Facilities IN PINGSHAN NEW DISTRICT}

\section{A. Development of Public Cultural Facilities}

Pingshan new district is located in the northeast of Shenzhen city edge, including Pingshan Street Offices, Kengzi Street Office, and large industrial zones. It covers an area of 168 square kilometers and is also the main industrial base in the east of Shenzhen city.

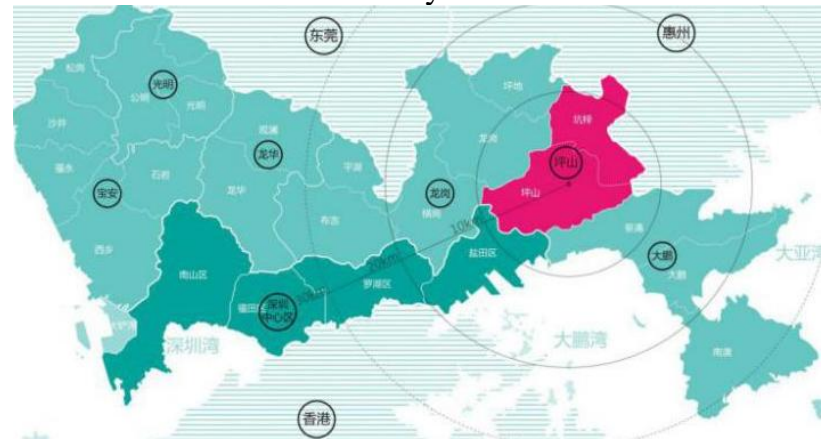

Figure 1. Location map of Pingshan new district

Pingshan community is currently in transition from the edge of the city village to city community stage, and community public cultural facilities construction is not perfect. The status of that includes cultural plaza, cultural activity room, library etc. But there is no independent place for cultural and recreational facilities, which is mainly based on the construction of public cultural space in the neighborhood committee. The library, cultural activity room, indoor activity space setting in the square will be built around the neighborhood. Because community neighborhood committee mainly uses administrative office functions and the establishment of facilities are lacking convenience. Therefore, most of the community residents and migrant workers rarely go to the office building for reading. At the same time, through the investigation of the current situation was informed that the library books are old, updated slowly, and cultural activities room with the standard is not perfect .However, the low levels of service and overall result in less attractive and mass participation is weak.

\section{B. Development of Community Cultural Facilities Based on Special Population Structure}

By December 2014.Pingshan household population reached 42700, the floating population reached 504700, accounting for $92 \%$ of the total population. The age of the floating population is mainly between 15 and 60 years old. Population foreign and the rejuvenation of population structure make the demand for quantity and type of community cultural facilities increased. Community not only to expend the scale of public cultural facilities, but also in accordance with the different population structure and its activity characteristic to complement and improve the corresponding facilities. Because the economic development of each community is different, and there are obvious differences in the quantity and quality of the facilities between the communities, so the distribution of facilities is not balanced .Meanwhile, public cultural facilities increase with the development of community and the increase of the population. Thus, it is difficult to meet the needs of residents only with the neighborhood as the core construction of cultural facilities.

\section{The Contradiction between the Construction of Public Cultural Facilities and the Land Ownership}

With the development of industrialization, Pingshan foreign population increases rapidly. From the perspective of profit maximization, local residents build a large number of private houses and commercial facilities to develop the leasing economy. Leading to extensive land use and urban village construction intensive. At the same time, under the influence of land expropriation and land transfer, the relationship between land ownership and land actual control is complex, current situation of land use and ownership fragmentation, buildings crowded, and the current land management system is lacking .Furthermore, with the increasing demand of public cultural facilities, how to choose the construction site is a challenge. The neighborhood committee facilities can not meet the needs of cultural facilities' service radius. And there is a complex 
situation of land ownership in the presence of cultural facilities.

\section{THE CHARACTERISTICS OF HAKKA CULTURE AND Tue Change of Status in the Process of URbanization}

\section{A. Pingshan Hakka Native Status Distribution and Spatial Characteristics}

Hakka culture is one of the characteristics of Shenzhen culture. Even the modern culture is brilliant; it is difficult to cover up the brilliance of Hakka culture. Pingshan New District has a rich Hakka cultural resources and profound historical and cultural heritage. There are 126 heritage sites which by Hakka as the main body.

Hakka Round House (also called wai dragon house, dragon house, turn round house, hakkas enclose dragon house) is the hakka culture of known feature of the domestic architecture. Hakka Round House is the traditional living space of the Hakka people. Pingshan Hakka village mainly in the "Circular" Architecture. In space layout, the main hall is the core of construction to house. There are three main halls. They are usually vertical. On the outside of hall, people build the horizontal house which perpendicular to the hall. In this way a "Three hall two horizontal" hall is created. "Three hall two horizontal" hall is the foundation of the Hakka residence hall.
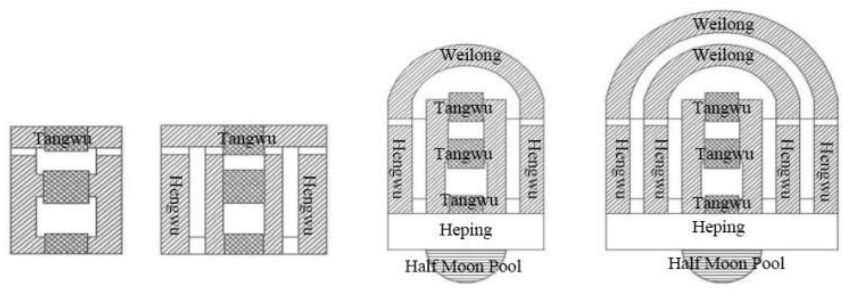

Figure 2. Hakka round house in Ping Shan new district

On this basis, people build Heping (The site of the front of the house) and Half Moon Pool in front of it, and behind the hall to build the Weilong (The room around the house). That forms the Weilong House which as the representative forms of Pingshan Hakka Round House. The Weilong can be built according to the needs of the function. With three halls as the core, to build defensive turrets around it, we can get a circle of buildings. Heping and Half Moon Pool are the main space for Hakka residents having outdoor activities. Heping is mainly used for grain drying and festival activities. The Half Moon Pool can be as fish ponds and regulate climate and prevent fires.

\section{B. The Developing Situation of Pingshan Hakka Native Cultural}

Due to the development of the urbanization, the rural construction has become increasingly prosperous. And it brings the bad impact and destruction of the Hakka history. The construction of modern residential area and the broad road near the old Hakka Enclosed make the village pattern of traditional Hakka houses suffering damage, and the original living atmosphere of the Hakka Round House gradually disappear. Then it brings the destruction and isolation of the traditional space. With the people's awareness of traditional cultural protection enhanced, a few of larger scale and distinctive Hakka Round House have been protected, and as the exhibition hall to display the Hakka Round House culture. But because the disrepair and protection work is not in place, most of the Hakka Enclosed were damaged to varying degrees. It can be found everywhere that the houses collapsed and walls damaged because of rain. The contradiction between Hakka culture, architecture style protection and the urbanization development of Pingshan New District have become increasingly prominent.

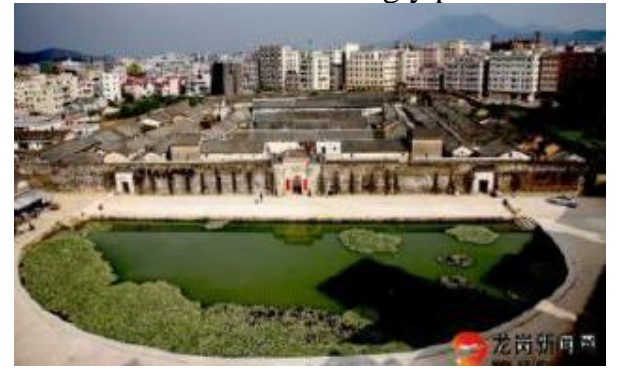

Figure 3. Aerial view of Da Wan Hakka Round House in Pingshan New district

Hakka Round House (also called wai dragon house, dragon house, turn round house, hakkas enclose dragon house) is the hakka culture of known feature of the domestic architecture. Hakka Round House is the traditional living space of the Hakka people. Pingshan Hakka village mainly in the "Circular" Architecture. In space layout, the main hall is the core of construction to house. There are three main halls. They are usually vertical. On the outside of hall, people build the horizontal house which perpendicular to the hall. In this way a "Three hall two horizontal" hall is created. "Three hall two horizontal" hall is the foundation of the Hakka residence hall.

\section{THE REgENERATION STRATEGY OF TRADITIONAL HaKKa ROUND House SPACE IN PINGSHAN NEW DistRICET}

\section{A. Function Expansion of Community Cultural Space}

Hakka Round House space is the foundation of Pingshan traditional culture. How to get effective protection and utilization in the process of urbanization is the key to maintain the continuation and inheritance of Hakka culture. Pingshan New District's urbanization development and the industrialization brought the influx of foreign population, which is the main factor that causes the communities public cultural facilities shortage and the destruction of Hakka Round House space. Therefore, from another angle to think, whether the community cultural facilities and the construction of the traditional Hakka Round House space protection can be combined with each other, in order to effectively expand the community cultural space and realizing the regeneration and utilization of Hakka Round House space. Ultimately change the embarrassing situation in the process of the traditional Hakka Round House space transformation, to find a continuous and futuristic development direction of the traditional culture space. 


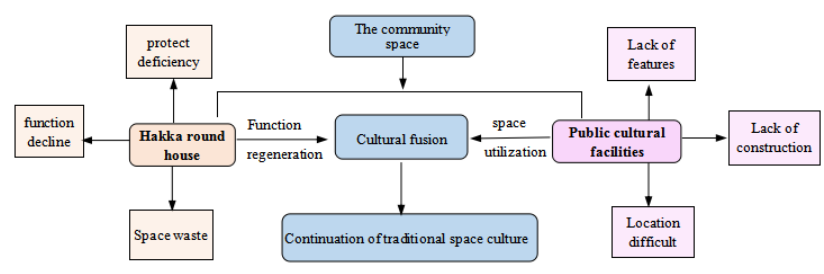

Figure 4. Function expansion of community culture and mode of space utilization

\section{B. The Protection and Renewal of the Traditional Living Space in the Community}

Protection of traditional living space is a process of functional change and cultural continuity. Simply protecting its original architecture and space form can only survive under the artificial repair and maintenance .It could not withstand the aging dilapidated days and months multiplying and the function elimination in the process of urbanization. Eventually lead to the cultural loss. So we must not only protect the original construction should also make it bear the corresponding functions in the process of the development of the modern community, becoming a part of the community public cultural space. In order to make it in the process of urbanization can continue to have the vitality of the development, to achieve the recycling of space.

\section{Stimulate the Vitality of Traditional Community Living Space}

The Hakka Round House space has distinct spatial characteristics .Most of its location is located in the center of the village. In front of the house, Heping and Moon Pool have a open space. Hengwu and Weilong in the main structure of Hakka house has formed the unique corridor space, most of them are also in the idle state .Community public cultural space can select the available Hakka Round House space to do the construction. Under the premise of protecting the main function of the current situation, to making full use of Hengwu and Weilong which are abandoned and idle. As the space of residents daily cultural activities community, cultural activities, exhibition and Hakka folk activities are hold regularly. Gathered the crowd, to stimulate the vitality of space. To make the old Hakka enclosed and the modernization function merged together, and the traditional architectural culture in the modern community public cultural atmosphere continues to continue.

\section{Pingshan HakKa Native Protection AND Cultural Space Utilization Mode}

\section{A. The Protection of Hakka Architecture}

The protection of Hakka Enclosed should be classified according to its historical value. The most important value of a class of Hakka houses should be fully protected, and delineate the scope of protection. Within the scope of protection, the land planning and department take over land for use. Strictly prohibit any transformation and construction which may cause damage to Hakka house and its surrounding environment. But also need to repair building, clean up the rental buildings and temporary additional architecture, as far as possible to restore the original appearance of the history. By repairing the common Hakka houses which can be used make the traditional space features reproduced. The periphery of traditional architecture should preserve its characteristic space pattern. The walls, gates and The Half Moon Pool are an important part of that. Should be repaired. Some new buildings and traditional architectural style are uncoordinated. We need to integrate the traditional scenes elements into the modern architecture of the block, to coordinate the look of the new and old buildings. Architectural scenes by using the cultural elements and symbols to change the facade of the building. We should integrate the traditional Hakka style into modern architecture, as far as possible to retain the theme structure of the existing building.People adopt the facade renovation method of the "dressing up", make it absorbed the detail decoration and color characteristics of Hakka history building, improve the appearance of the building group, and coordinate the overall style of the building.
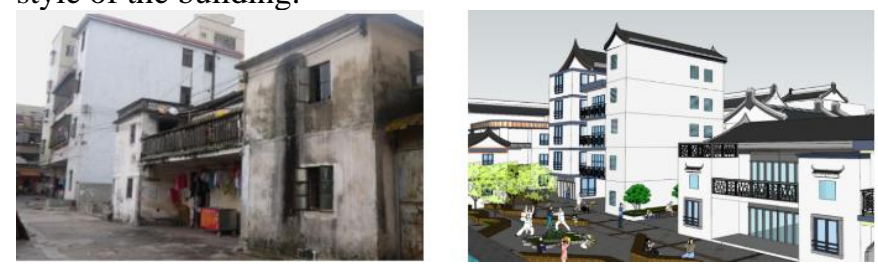

Figure 5. Contrast in facade and renovation of surrounding environment before and after

\section{B. The Regenerative Function of the Hakka Enclosed Interior Space}

The central room acts as the core of the building group for the Hakka Round House interior space. With the decline of traditional family living mode, the central room gradually evolved into the ancestor worship hall. While the surrounding Hengwu also changed, the traditional Hakka house has evolved into many rental housing units which rent to migrant workers, or became function loss space. In the strategy of renewal and regeneration of living space, we need to respect the inheritance of traditional culture and be as a foundation, to repair and protect the core room, which function is offer sacrifices to gods or ancestors. That is the continuation of Hakka traditional family life. On the basis of maintaining the original style of the surrounding Hengwu space and ancillary spaces endow with the new community culture function, set up the different cultural activity room, library, reading room and other public cultural space. At the same time, should be the roadway as a display and publicity space, eliminate the original monotonous and closed atmosphere, and inject new vitality. The Hakka Enclosed space utilization not only solve the land tension problem about the community cultural, but also make the community residents experienced a modern public cultural functions in the traditional cultural space. Becoming the core of the surrounding residents of the space, to achieve the function of the space regeneration. 


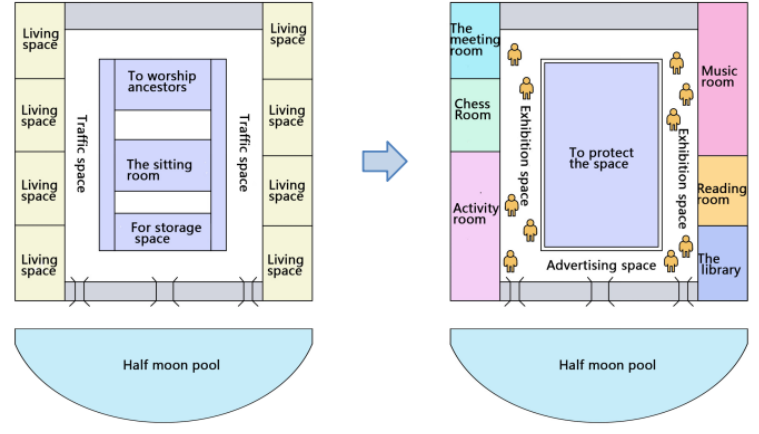

Figure 6. Space function to update

\section{Regeneration and Utilization of Hakka Enclosed External Space}

The Geomantic omen pond and the Heping are the main features of the external Hakka Round House public space. The main form of Geomamtic omen pond is Half Moon Pool, around the building space form banded pond, to have a unique style of outdoor space and have their own space characteristics. In the use of the external space, mainly to the residents of public activities as the theme, using the space.
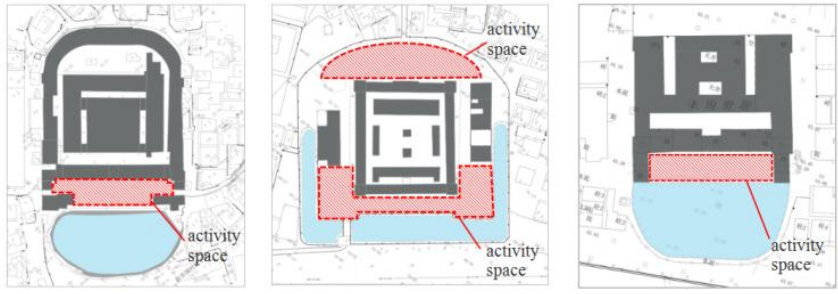

Figure 7. Using pattern of outer space in Hakka Round House of Ping Shan

Spacious HePing can be arranged fitness path, stadium and other outdoor venues. At the same time also can set up the leisure chair, forms the resident daily exchange and the leisure activity cultural square. In the technical aspects, the Geomantic omen pond can improve its water quality. In form by creating a hydrophilic platform and simple space reform make it become a characteristic residents' hydrophilic space. Through the regeneration and utilization of space can reproduce the prosperity of the past and enhance the status of the cultural life in the modern community. To realize the Hakka space culture enduring in the modern development process.

\section{Safeguards of Hakka House Regeneration and Utilization}

The regeneration and utilization of traditional Hakka Round House space, the suggested approach is the government guidance, the village collective spontaneous financing, or renewal and improvement. Give the function of the public culture to the traditional architecture community. The Hakka house which is not effectively protected in the community, community may ask for the owner's will, choosing leasing and other models to have utilization. Through the government to the community public cultural facilities construction and the way of enterprise management to ensure the daily maintenance management. Community should undertake the responsibility for the daily maintenance and management of Hakka, and become an important part of the community public cultural space.

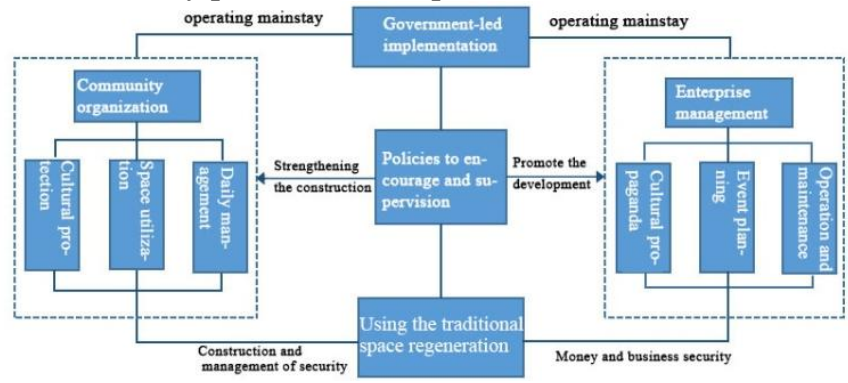

Figure 8. The pattern of safeguard measures

\section{REFERENCES}

[1] J. Ye Zurun, Traditional settlements environment space structure analysis. Architectural Journal, 2001.

[2] J. Ma Hang. The continuation of Chinese traditional villages and evolution, rethinking of traditional settlements planning. Urban Planning Forum, 2006. 